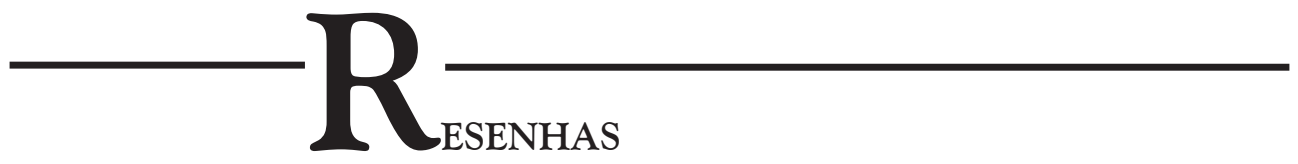

BARNETT, Michael. The Rastafari Movement: a North American and Caribbean Perspective. Routledge, 2018, 190pp.

Fernando Vieira de Freitas

\title{
UMA PERSPECTIVA CONTEMPORÂNEA SOBRE O MOVIMENTO RASTAFÁRI
}

O movimento Rastafári foi gestado no auge das revoltas populares que atravessaram a Jamaica e quase todo o Caribe durante a década de 1930. O coroamento de Haile Selassie I - também denominado Rás Tafári - como imperador da Etiópia em agosto de 1930 foi o evento que marcou a origem histórica do movimento Rastafári na Jamaica. A ascensão do "imperador negro" foi a fagulha que fez brotar um movimento ainda em gestação, formado principalmente pela classe negra trabalhadora rural e urbana jamaicana, e que viria a reivindicar a emancipação e a autonomia dos antigos descendentes de escravos; o caráter sagrado da população negra, a partir da sua ligação direta com a dinastia de Rei Salomão, por meio de Haile Selassie I; a relação ontológica com o continente africano (que deu forma às demandas por repatriação); a sacralidade da relação com a natureza e o uso do "natural" em oposição ao "industrial/processado"; o uso da cannabis e dos dreadlocks etc. No entanto, grande parte dessas e outras práticas e fundamentos que caracterizavam o movimento Rastafári sofreu modificações ao longo do tempo, o que produziu alterações importantes nas bases que o constituíam desde sua fundação.

É nesse sentido que em seu livro "The Rastafari Movement: a North American and Caribbean Perspective", o jamaicano Michael Barnett busca delinear os fundamentos ideológicos do Rastafári, observando como eles surgiram e se transfor- 
maram ao longo do tempo entre as principais casas ("mansions") na Jamaica e nos Estados Unidos. Essa questão central constitui o eixo que permite ao autor explorar temas como gênero, globalização, teologia, organização interna, linguagem e simbologia, ao mesmo tempo em que investiga como o desenvolvimento dessas dimensões culminou na formação do Rastafári contemporâneo. Uma das características mais notáveis da obra e que certamente marca todo o desenvolvimento do argumento é o fato de ter sido fruto do trabalho não só de um estudioso do Rastafári, mas também de um membro ativo do movimento.

No primeiro e mais longo capítulo de livro referido, Barnett dedica-se a oferecer um panorama geral das três filosofias centrais na formação da identidade Rastafári: o Pan-Africanismo, o Nacionalismo Negro e o Etiopianismo. $\mathrm{O}$ autor discute a fundação do Pan-Africanismo, apontando a existência de uma fundação prática, que se deu no exato momento em que os africanos pisaram os pés no outro lado do Atlântico, e outra fundação conceitual, formada pela elaboração teórica e pela origem do movimento pan-africanista. As raízes desse movimento foram gestadas no final do século XIX pelos intelectuais negros (W.E.B du Bois, Marcus Garvey e vários outros) na diáspora no Caribe e nos EUA que, de maneira geral, defendiam a importância de uma solidariedade negra ao redor do mundo, a integridade da civilização africana e a necessidade de sua redenção perante a história da opressão branca-ocidental. O Nacionalismo Negro, por sua vez, foi um movimento originado nos Estados Unidos, já na primeira metade do século XIX, a partir dos conflitos raciais locais, e tem como fundamentos a solidariedade racial, o orgulho da herança cultural negra e a busca de autonomia e independência da população negra pertencente a um território nacional específico. Aqui, ao contrário do internacionalismo existente no pan-africanismo, o compromisso com a busca de uma identidade africana não está necessariamente presente.

No entanto, especialmente importante para o desenvolvimento do Rastafári é o Etiopianismo, cujas primeiras aparições se deram entre os Wesleyanos na África do Sul em 1884 (Barnett 2018:8). Este se apresenta como um movimento religioso, pró-negro e africanista, baseado em fundamentos espirituais que situam a população negra como o povo escolhido, e a Etiópia (ou o continente africano) como território sagrado, partindo de uma exegese particular de livros do Antigo Testamento. Na ilha jamaicana, o Etiopianismo mescla-se à Igreja Batista Negra (um tipo de "Cristianismo africanizado" presente na ilha desde o século XVIII) e ao Revivalismo do final do século XIX (movimento de ressurgimento de religiões de inspiração africana como o Myal, o Obeah e a Pukumina) para consolidar a principal base teológica do movimento Rastafári que viria a surgir em 1930.

Dura1nte o desenvolvimento do Rastafári, pesou, sobretudo, a influência do pan-africanismo religioso de Marcus Garvey, sem sombra de dúvidas um dos líderes negros que mais contribuiu com a base ideológica do movimento negro moderno, principalmente na Jamaica e nos EUA. Especialmente popular durante a primeira e parte da segunda metade do século XX, o Garveísmo girava em torno da noção de que todos os povos de ancestralidade africana deveriam trabalhar conjuntamente 
pelo seu próprio progresso. A busca pela construção de uma identidade negra positiva, segundo Garvey, fundamentava-se em uma leitura das escrituras que conclamava os negros a "enxergar Deus a partir de seus próprios olhos, [...] o Deus da Etiópia, o Deus eterno, o Deus Negro". Diante disso, quando Haile Selassie I foi coroado imperador da Etiópia em 1930, os Rastafáris tomaram o anúncio de Garvey como uma profecia que declarava Selassie I como o Deus negro das Escrituras (Barnett 2018:9).

Barnett prossegue com uma análise histórica e teológica do movimento Rastafári na Jamaica que se divide em cinco "épocas": a primeira trata dos primeiros anos de fundação do movimento e dos primeiros líderes, como Leonard Howell, Robert Hinds, Archibald Dunkley e Joseph Ribert (1930-1948); a segunda, do surgimento da segunda geração de lideranças Rastafári, como Mortimo Plano, Prince Emmanuel I e Bongo Wato, da formação das primeiras "mansions", e do advento do uso do "dreadlock" e da Ganja (1948-1968); a terceira, das relações do movimento com a música Reggae (1968-1981); a quarta trata da morte da segunda geração de líderes e a crise existencial do movimento (1981-2007); e a quinta e última época, que se inicia em setembro de 2007, aborda a entrada do Rastafári no "novo milênio", segundo o Calendário Etíope, marcando uma reconfiguração organizacional das principais casas que passam a ser governadas por conselhos e não por lideranças carismáticas.

No segundo e terceiro capítulos, são apresentados os modos de organização do movimento Rastafári, explicitado enquanto uma associação distintamente heterogênea e descentralizada, na qual a autoridade repousa em células e ramificações que agem independentemente umas das outras, mas que se mantêm unidas pelo compartilhamento de um ethos simbólico, ritualístico e ideológico comum. Apesar do grau relativamente baixo de institucionalização, três importantes "mansions" Rastafári permanecem como as organizações mais proeminentes ainda hoje: a casa de "Boboshanti", a "Nyahbinghi Order", as "Twelve Tribes of Israel".

Ainda que compartilhem diversos pressupostos, as casas se diferenciam nas maneiras em que abordam, ritual, simbólica e teologicamente, exatamente essas pressuposições comuns. Uma das principais distinções é a questão de gênero e o papel das mulheres nos rituais Rastafári, discutidos no quarto capítulo. Aqui, o autor chama atenção sobre como as casas incorporam de distintas maneiras as mulheres em sua ritualística, apontando o protagonismo quase sempre invisibilizado das Rastawomans no desenvolvimento de relações de gênero menos hierarquizadas e os avanços dos Rastamans em contribuir com essa evolução, denunciando a necessidade de progredir no empoderamento das mulheres no Rastafári.

O quinto capítulo é uma miscelânea curta sobre simbologia e linguagem Rastafári e é seguido, no sexto capítulo, pela análise do processo de globalização do movimento e por pesquisas de campo do autor nos Estados Unidos. Aqui é apresentado um dos traços mais notáveis que marcaram o desenvolvimento do movimento Rastafári: seu enorme potencial de mundialização. Grande parte dos líderes e das figuras centrais do movimento, como Marcus Garvey, Leonard Howell e Bob Marley, estiveram sempre em viagens ou em contato com lideranças de outros países. Importante 
também foi a migração de jamaicanos principalmente para a Inglaterra e os Estados Unidos, mas também para outros países como Canadá, Japão e Brasil, nos quais o Rastafári é consideravelmente reconhecido.

O sétimo capítulo elenca uma série de entrevistas realizadas por Barnett em trabalhos de campo entre a comunidade Rastafári no sul da Flórida nos Estados Unidos. Nesse trabalho são entrevistados anciões Rastafáris e lideranças mais jovens, pertencentes a todas as três casas que foram estabelecidas nessa comunidade. A intenção é inquirir sobre algumas das diferenças teológicas, ideológicas e programáticas entre as casas Rastafáris, como a utilização ou não do título de "Israelitas" pelos seus membros, a priorização ou não das políticas de repatriação para a África e a questão da aceitação de Rastas brancos em suas fileiras.

Mantendo o foco no continente norte-americano, no oitavo capítulo o autor procura aprofundar o estudo sobre a identidade Rastafári a partir de uma análise comparativa com outros movimentos dos Estados Unidos que também professam a identidade racial a partir de uma teologia especificamente negra, como os Israelitas Negros e, especialmente, a Nação do Islã.

O nono capítulo finaliza o livro e apresenta um balanço geral com reflexões próprias de Barnett que buscam iluminar "onde o movimento Rastafári atualmente se situa em termos ideológicos e filosóficos e como ele precisa reorientar a si mesmo para atingir qualquer um de seus objetivos" (Barnett 2018:145). Aqui o autor retoma o tema sobre como o "novo milênio" precipitou o movimento Rastafári num processo de reformulação que, para obter sucesso, deve ser guiado em torno de uma maior institucionalização e união entre as diferentes células, casas e instituições que conformam as frentes organizadas do movimento.

$* * *$

Barnett realiza um extenso exame dos fundamentos teológicos do movimento Rastafári, abordando o Etiopianismo, as religiões afro-jamaicanas e as interpretações próprias do Antigo Testamento feitas pelos Rastas. Ainda que hajam exceções, grande parte da literatura sobre o movimento Rastafári tende a privilegiar os aspectos políticos e culturais em detrimento da dimensão religiosa do Rastafári, que talvez seja a mais central. O mesmo ocorre com Marcus Garvey, cujo pan-africanismo religioso também é pouco estudado. A perspectiva multissituada do autor permite estabelecer vínculos entre o desenvolvimento do Rastafári na Jamaica e a circulação de novas formas de pensamento em voga entre os movimentos negros norte-americanos da primeira e da segunda metade do século XX. Nesse sentido, não só é ressaltado o caráter global do Rastafári, mas também suas interseções com a própria diáspora contemporânea da população negra caribenha para os EUA, Europa e outros países da América Latina. Os relatos coletados pelo autor em sua pesquisa de campo fornecem indícios de primeira mão para compreender como o Rastafári se desenvolveu nessas localidades fora da ilha jamaicana. 
Um traço original do trabalho de Barnett é o argumento sobre a reconfiguração atual (situada historicamente no "Novo Milênio") das organizações Rastafári em direção aos conselhos deliberativos no lugar das antigas "lideranças carismáticas". Observando esse momento histórico, o livro parte do entendimento de que o movimento Rastafári contemporâneo precisa compreender a si mesmo para evoluir de maneira "positiva", e é nesse sentido que Barnett procura oferecer uma contribuição para esse processo. Isso concede ao livro uma característica política, baseada certamente na posição de Barnett enquanto Rastafári, mas que não priva o texto do seu rigor acadêmico. Ao contrário, a junção positiva dessas duas dimensões é operada de maneira a proporcionar uma análise bastante única do movimento, construída a partir de perspectivas teóricas e metodológicas variadas, indo desde a historiografia e a antropologia aos estudos da religião.

O livro transita entre a fragmentação e a institucionalização do Rastafári, garantindo ao argumento uma mobilidade que faz jus ao dinamismo característico do movimento. Ainda assim, o polo das instituições é sem nenhuma dúvida privilegiado durante grande parte do texto, ainda que o autor procure equilibrar esse desnível em alguns momentos. De todo modo, isso está em conformidade com a proposta do livro de investigar as casas Rastafári, o que certamente garante destaque ao lado organizacional.

O autor também contribui com o estudo da dimensão do gênero, em geral quase ausente nos estudos sobre o movimento Rastafári, ainda que, no livro, o tema seja tocado de maneira apenas superficial. Ainda assim, são satisfatoriamente apresentadas as principais autoras que escreveram sobre o assunto, como Imani Tafari- Ama, Obiagele Lake, Barbara Lake-Hannah e Maureen Rowe, indicando referências que podem ser usadas para pesquisas futuras. Outra ausência notável é o debate sobre homossexualidade/transexualidade que ainda permanece sendo, talvez, um dos maiores tabus nos escritos sobre o Rastafári.

Por fim, o livro oferece uma importante contribuição para os estudos do movimento Rastafári, sob a valiosa perspectiva de um cientista social insider. O resultado dessa experiência está particularmente presente em "The Rastafari Movement", que proporciona uma análise atualizada e bem construída das bases teológicas e ideológicas do movimento Rastafári, bem como suas diferentes acepções e desenvolvimento ao longo do tempo.

Submetido em: 15/01/2018 Aceito em: 17/08/2018

Fernando Vieira de Freitas (fernandosemba@gmail.com) Doutorando em Antropologia Social no Programa de Pós-Graduação em Antropologia Social, Museu Nacional, Universidade Federal do Rio de Janeiro - Rio de Janeiro - RJ - Brasil. Membro do Laboratório de Antropologia e História (LAH/PPGAS). 